\title{
The effects of different interpolated ITI stimulus-conditioned stimulus intervals on the acquisition of the classically conditioned nictitating membrane response of the rabbit ${ }^{1}$
}

JAMES D, PAPSDORF AND NEIL M. KETTLEWELL THE UNIVERSITY OF MICHIGAN

Acquisition rates of the rabbit's classically conditioned nictitating membrane response were determined for three experimental groups, subjected to $5 \mathrm{sec}$ white noise bursts at 10 , 30 , or 50 sec after CS-US offset, and compared with the performance of a non-noise control group. Bursts of white noise in the ITI significantly depressed conditioning rates, with the greatest depression produced by the $30 \mathrm{sec}$ post-US burst.

Kettlewell \& Papsdorf (1967) reported that $10 \mathrm{sec}$ of illumination of a darkened experimental enclosure in the middle of an extensive (90 sec) ITI attenuated the conditioning rate of the nictitating membrane response. It was suggested that this depression could have been due to an inhibitory effect, such as a greater reactive inhibition (Hull, 1943) or an attention-competing orientation reaction (Pennypacker, 1964), present at the time of CS onset. It was also suggested that the depression could have been produced by a suppressive effect not present at the time of CS onset, such as disruption of an ITI consolidation process by light-elicited orientation reactions. The purpose of the present investigation was to provide further evidence bearing on the validity of these formulations by comparing the conditioning rates of Ss receiving ITI stimuli at 10,30 , or $50 \mathrm{sec}$ after CS-US termination. The consolidation disruption hypothesis would predict that the closer such stimuli are to CS-US offset, the greater their depressive effect on conditioning, while the "CS-inhibition" hypothesis would relegate the greater depression to stimuli most temporally remote from CS-US termination. Finally, in order to determine the generallty of the depression effect of ITI stimuli, enclosure illumination was replaced with bursts of white noise.

Method

The apparatus and procedure employed in classical conditioning of the nictitating membrane response of the rabbit in the Michigan laboratory has been described by Kettlewell \& Papsdorf (1967). On each of the atx conditioning sessions Ss received 15 CS-US pairings at a fixed ITI of $60 \mathrm{sec}$. The CS, a $93 \mathrm{~dB}, 1000 \mathrm{cps}$ tone, was presented for $600 \mathrm{msec}$, wh the US, a $3.0 \mathrm{~mA}$. 60 cps shock, overlapping the last $100 \mathrm{msec}$ of CS presentation. Thirty Ss were randomly assigned to each of the three experimental conditions $(n=10)$ which consisted of presenting a 5 sec, $73 \mathrm{~dB}$. white noise burst

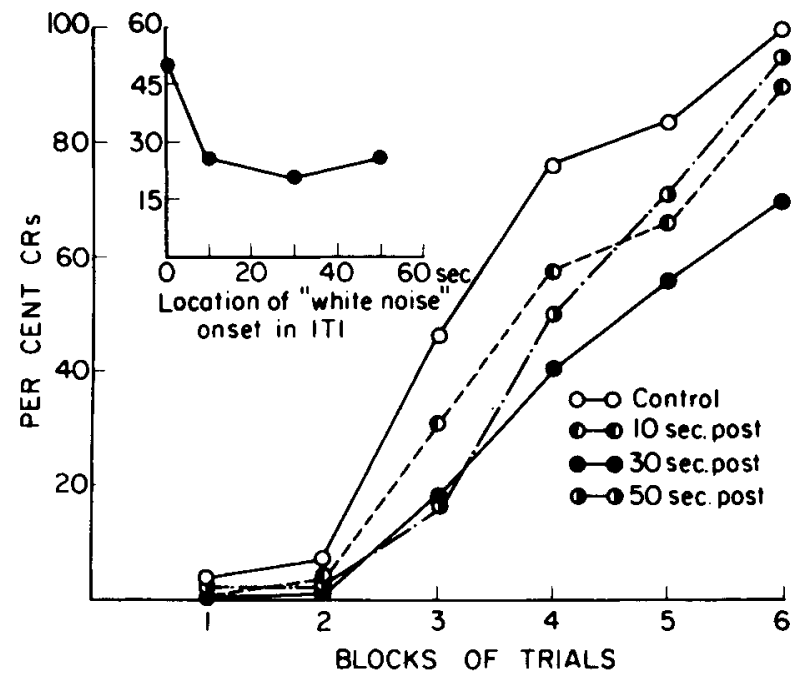

Fig. 1. Percentage CRs on each of the 6 conditioning sessions and (Inset) collaped over the 6 sessions. The control data point in the Inset lies at the 0 abscisea valve.

at 10 ("10 sec post"), 30 ("30 sec post") or 50 ("50 sec post') sec after CS-US offset. The remaining Ss were trained under the non-noise control conditions. Results

Figure 1 presents the percentage of CRs across blocks of 15 trials for the four groups with mean performance across the six conditioning sessions plotted in the Inset. The three groups subjected to ITI-interpolated bursts of white noise conditioned more slowly than the Control Ss who attained the $100 \%$ CR level on the last conditioning session. The conditioning rate of the "30 sec post" Ss was the most depressed, with the group attaining only the $70 \%$ level by Session 6 , while the performance curves of the " $10 \mathrm{sec}$ post" and "50 sec post" Ss were essentially identical, and attained the 90-95\% level by the last session. Analysis of variance of percentage CRs across blocks of 15 trials yielded only a significant Group Effect ( $F=4.59$, df $=3 / 36$, $p<$ .01) and, of course, Trial Blocks Effect. Application of the Newman Keuls test (Winer, 1962) to the four CR means (Inset) indicated that the "30 sec post" group's performance fell significantly below the means of the 
other conditions while the conditioning levels of the "10 sec post" and "50 sec post" groups, though significantly below that of the control's, did not differ significantly from each other (all significant $p$ values at $<.05$ ). Discussion

The greater reduction in conditioning rates accompanying ITI interpolation of the " 30 sec post" US white noise burst relative to that produced by the "50 sec post" US burst provides some basis for attributing the depressive effects of certain ITI-interpolated stimuli to the disruption of an ITI consolidation process, rather than to greater accumulation of reactive inhibition (Hull, 1943) or interference from attention-competing orientation reactions (Pennypacker, 1966). Thus, if consolidation of a neurally coded tone-shock contingency proceeds in the ITI, the degree of vulnerability to disruptive events should vary inversely with time, a prediction confirmed by the $30 \mathrm{sec}$ vs $50 \mathrm{sec}$ white noise burst data points. If it is assumed that such stimuli as enclosure illumination and white noise bursts can disrupt ITI consolidation, presumably because the general cortical and/or subcortical activity changes which they elicit disrupt the neural tone-shock code, then the desynchronizing effect of the shock US should also serve to disrupt consolidation. Thus it is suggested that CS-US presentation on Trial $\mathrm{N}$ activates a population of neural elements whose firing pattern codes the tone-shock contingency. This dynamic pattern, or "short-term store" consolidates with time to a relatively invulnerable "long-term store," and those elements of the initial population which have not consolidated by the time of Trial $\mathrm{N}+1$ are disrupted by the US of this trial. Another population of neural elements is again activated by the tone-shock contingency of Trial $\mathrm{N}+1$ and the cycle is repeated.

Opposed to this ITI consolidation hypothesis is the observation that the "10 sec post" US ITI stimulus had less of a depressing effect than did the "30 sec post" US ITI stimulus. One possible reason for this result may be that the extensive cortical activation induced by the US partially masks Ss detection of the "10 sec post" US ITI stimulus. While the simplicity of the masking hypothesis is appealing, an alternate explanation, consolidation delay, has some merit as well. Thus the prolonged and extensive cortical and/or subcortical activity changes produced by the US may delay the consolidation process until a less active and therefore more optimal level of excitation is approached. It is conceivable that during this interval the neural ana$\log$ is relatively immune to disturbing influences and only when the transfer between short-term and longterm representations occur, does it become vulnerable to disruption. The invertigation of Albert (1966) suggesting the presence of a consolidation "template" in interhemispheric transfer of an avoidance response provides some empirical support for the existence of a mechanism required by the "delay of consolidation" hypothesis. As applied to the present investigation the "template" is seen as a temporary protective buffer which provides an input for the consolidative processes underlying a more permanent storage only when cortical and/or subcortical activity returns to a given level. It is assumed that this level is exceeded for some time after US termination, and that during this period disruptive stimuli, of the magnitude used in the present investigation, have their depressive effects attenuated. References

ALBERT, D. J. The effect of spreading depression on the consolidation of learning. Neurophysiologia, 1966, 4, 49-64.

HULL, C. L. Principles of behavior. New York: Appleton-CenturyCrofts, 1943.

KETTLEWELL, NEIL M., \& PAPSDORF, JAMES D. The effects of an interpolated ITI stimulus on classical conditioning of the nictitating membrane response of the rabbit. Psychon. Sci. 1967, 9, 257-258.

PENNYPACKER, H. S. External inhibition of the conditioned eyelid reflex. In G. A. Kimble (Ed.) Foundations of conditioning and learning. New York: Appleton-Century-Crofts, 1967, 528-544.

WINER, B. J. Statistical principles in experimental design. New York: McGraw-Hill, 1962, 80-85.

Notes

1. This study was supported in part by grants from the Office of Research Administration, University of Michigan, and the National Institutes of Mental Health to James D. Papsdorf, NIH MH 12504-01. 